\title{
Research
}

\section{Functional Links Between Biodiversity, Livelihoods, and Culture in a Hani Swidden Landscape in Southwest China}

\author{
${\text { Jianchu } X u^{1,2}}$ Louis Lebel $^{3}{ }^{3}$, and $\underline{\text { Janet Sturgeon }}^{4}$
}

\begin{abstract}
The landscape of Mengsong, southwest China, was biologically diverse until recently due to historical biogeographical processes overlain by the swidden-cultivation practices of the Hani who migrated there several centuries ago. Our research sought to understand how the Hani adjusted their livelihoods to new policies, markets, and technologies, and the consequences for biodiversity conservation. We combined landscape, plot, and household surveys, interviews, and reviews of secondary documents, to reconstruct the major changes and responses to challenges in the social-ecological system over previous decades. Significant changes from closed to open canopy of secondary-forest vegetation took place between 1965-1993 and from open-canopy to closed-canopy forest between 1993-2006, mostly explainable by changes in state land-use policies and the market economy. Most remaining swidden-fallow succession had been converted into tea or rubber plantations. Swidden-fallow fields used to contain significant levels of biological diversity. Until 2000, biodiversity served several important ecological and social functions in the Hani livelihood system. Indigenous institutions were often functional, for example, linked to fire control, soil management, and watershed protection. For centuries, the Hani had detailed knowledge of the landscape, helping them to adjust rapidly to ecological disturbances and changes in production demands. The Hani understood succession processes that enabled them to carry out long-term land-management strategies. Recent government policies and market dynamics have simplified livelihoods and landscapes, seriously reducing biodiversity, but greatly increasing the area of closed-canopy forest (including plantations) and undermining the usefulness of Hani knowledge and land-use institutions. Meeting both conservation and development objectives in this landscape will require new functional links between sustainable livelihoods, culture, and biodiversity, rather than seeking to recreate the past.
\end{abstract}

Key Words: biodiversity; cash crops; conservation and development; culture; fallow management; Hani people; livelihoods; monoculture; swidden landscape

\section{INTRODUCTION}

Swidden-farming systems have emerged repeatedly in tropical landscapes, transforming them, and often sustaining them in particular configurations for long periods (Conklin 1957, Spencer 1966). The landscape mosaics they create are often high in agrobiodiversity and, over time, can create complex functional links between livelihoods, biodiversity, and culture that can be highly resilient (Brookfield et al. 2003, Rerksasem et al. 2009). However, in most places around the world, these systems are being transformed by conservation and development policies and the emergence of new markets for cash crops (Sturgeon and Menzies 2008). In many cases, these rapid changes have disrupted crucial links that helped make these systems resilient, and they have not yet been replaced by new links in the new configurations of landscapes and livelihoods.

The Hani (known to themselves and in Thailand as the Akha) were originally from Hong He in the Red River region of central Yunnan and probably moved into Xishuangbanna around the middle of the $18^{\text {th }}$ century. Mengsong lies on the border of Myanmar in Jinghong County in southern Xishuangbanna, in the southwest of China. River valleys in the warm subtropical zone were occupied by Dai and other ethnic groups from whom the Hani learned to practice swidden cultivation in the vacant temperate 
uplands. The Hani maintained complex social networks with the lowland Dai, the Bulang in the middle hills, and the highland Lahu, receiving ecological services from upland ecosystems and local livelihoods through product exchange.

Changes over previous decades led to a series of challenges to Hani livelihoods. The diverse landscapes of Mengsong and culture of the Hani were factors in their capacity to respond to these challenges (Xu et al. 2005a). Although the Hani have a tradition of managing nature (Pei and Luo 2000, Xu and Melick 2007), their efforts are not recognized by the government (Xu et al. 1999, Xu 2006a).

This study was undertaken to describe and explain how recent government reforms in forest and agricultural land policies and market integration have reconfigured landscapes and functional links between livelihoods, biodiversity, and culture in Mengsong. We synthesize and expand on past studies by presenting new empirical data and analyses based on our research between 1989-2007. Evidence from social, ecological, and policy studies indicates that it was the reciprocal, functional links between biodiversity, culture, and livelihoods that provided long-term resilience and incentives for conservation (Folke et al. 2003, Berkes 2006). These were the links that less nuanced paradigms of conservation and development have severed, threatening both livelihoods and biodiversity in Mengsong.

\section{METHODS}

\section{Study Site}

Mengsong is an important subwatershed of the Lancang (Mekong) River (Fig. 1), situated upstream. It is composed of 11 hamlets, 10 of which are Hani, and the other is Lahu. In 2007, there were 2488 people living in 549 households in an area of approximately $100 \mathrm{~km}^{2}$, at elevations between 800 $2000 \mathrm{~m}$.

Mengsong has a subtropical climate influenced by the Indian monsoon. The annual mean temperature is $18^{\circ} \mathrm{C}$. Rainfall is between $1600-1800 \mathrm{~mm}, 80 \%$ of which is concentrated from May-October. Soil is laterite (up to $800 \mathrm{~m}$ ) to lateritic red (800-1500 $\mathrm{m})$ and red soil (1500-2100 m). Vegetation varies with altitude and the mosaic distribution according to microenvironments and past human activities (Fig. 2). The three primary forest types are southsubtropical evergreen broadleaf forest, tropicalmontane rainforest and tropical-seasonal rainforest (Zhang and Cao 1995). Xishuangbanna is the most biodiverse region in China. Although it represents only $0.2 \%$ of the national territory, it has approximately 5000 higher plant species $(16 \%$ of the national total), 102 species of mammals (22\%), 427 species of birds (36\%), and 98 species of amphibians and reptiles (15\%) (Zhang and Cao 1995).

\section{Mapping Land-use and Land-cover Change}

We studied land-use and land-cover change in 1994-1995 and 2005-2007 and identified three main types of land use: closed-canopy forest, opencanopy or swidden-fallow fields (open canopy), and intensive-agricultural land. We collected land-use history narratives from village chiefs, community leaders, and the elderly (Xu et al. 1999). We used 1965 aerial photographs, a Landsat image dated March 1993, and a SPOT image dated April 2006, to construct a spatial database with knowledgebased classification. We recognized the following major types of land use in the photographs: secondary growth (further classified into closed canopy, open canopy, and grass and bushes), active swidden, and paddy, as well as emerging land-use types such as rubber and tea plantation, reservoir, and others. Land-cover types in the Landsat and SPOT images were classified using ERDAS image software and then registered to a topographic base map (1:25 000) and digitized for entry into a geographic information system (ArcInfo). We verified classifications in the field at 250 points, and carried out participatory mapping of the cultural landscape with a geographical positioning system. The 1994 land-use survey of Xishuangbanna (1:25 000) was also used as a reference and was found to be $90 \%$ reliable (Liu et al. 2002).

\section{Assessing Biological Diversity}

In 1989, we carried out a rapid biodiversity inventory that included species collected, managed, and cultivated by the Hani (Xu 1990). In 1995, we followed up with a participatory biodiversity assessment that paid particular attention to the inventory of ethnobotanical knowledge, and innovations and practices related to the use of 
Figure 1. Map of the Mengsong region in Yunnan Province, southwest China.

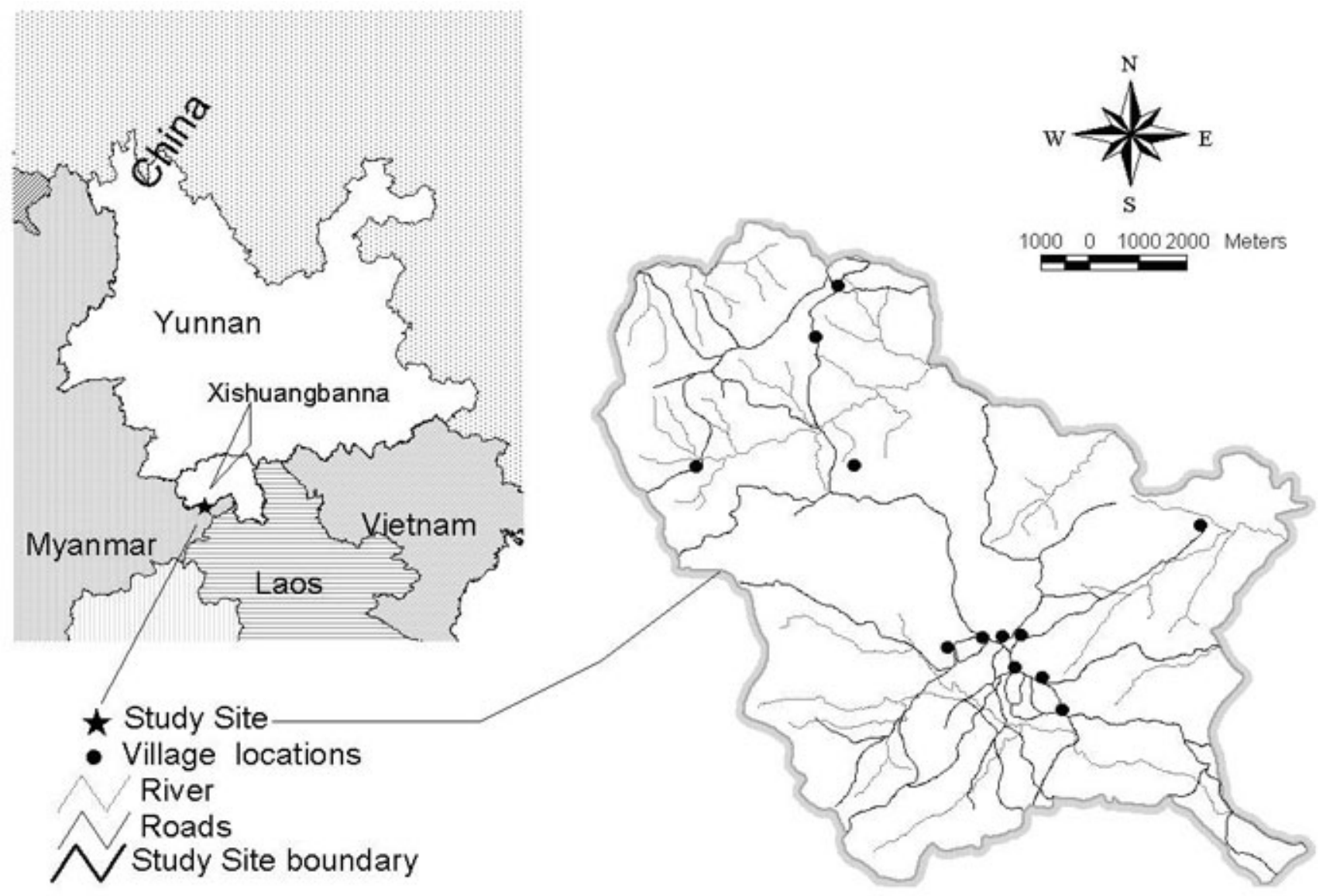

biodiversity, management of swidden fallows, maintenance of ecosystem services, and inheritance of cultural values (Pei et al. 1997). We obtained quantitative measurements of species composition, individuals, dominance, similarity indices, and Shannon-Wiener biodiversity indices in 1993-1994 using quadrat sampling (10 x $10 \mathrm{~m}$ plots for woody species and $1 \mathrm{x} 1 \mathrm{~m}$ subplots for grass) in the natural forest or closed canopy, or swidden-fallow fields at various successional stages along north-south transects (Smith 1980). Species composition of plots were compared using nonmetric multidimensional scaling analysis in SPSS software based on a matrix of pair-wise species similarityindex values.

\section{Identifying Cultural Landscapes and Institutions}

Our team carried out sociocultural studies from 1989-2007 and interviewed key informants, including current village heads, traditional village chiefs, elders, farmers, women from 11 hamlets in Mengsong, individuals in neighboring communities, and government agencies. We wanted to understand local institutions governing access to natural resources, interactions among different social groups and networks, and key external drivers for landscape transformations. To this end, we: 
Figure 2. A typical landscape in the Mengsong region of Yunnan Province, southwest China.

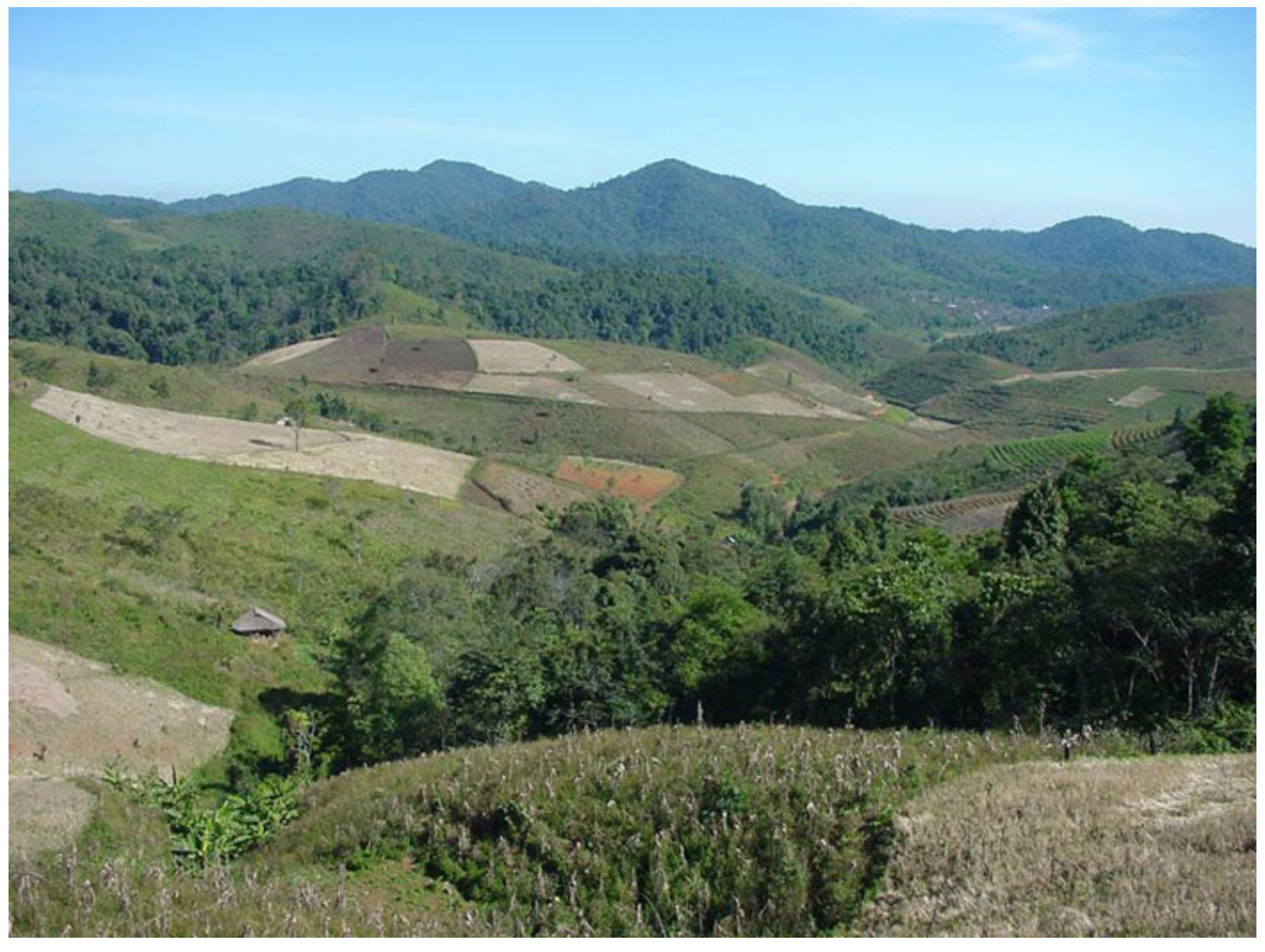

- $\quad$ Listed customary and statutory institutions reconstructing natural landscapes, paying attention to a large community-protected rattan forest (called "sangpabawa," meaning a place for the protection of rattan), and other locally protected forests such as firebreak evergreen broadleaf trees and jungle tea in the natural, cemetery, and sacred forests. We assessed impacts of state policies on forest tenure and land-use change.

- Identified locally managed swidden fallows, reconstructed customary and official boundaries (in particular, demarcated-forest tenure and swidden fields) in 1983 at the hamlet level, and interviewed key people about the history of land use (including years of cultivation and fallow) to understand landscape transformation.

- Mapped permanent agricultural lands, old and newly constructed paddy fields, terraced tea gardens, and rubber plantations at the landscape level supported by government policies for poverty alleviation, and reviewed histories. 


\section{Understanding Livelihood Dynamics}

Our team carried out socioeconomic household surveys in 1989-1990, 1997, and 2002-2003, and collected secondary socioeconomic data, including population, land allocation, and sizeable main cash incomes, from the Mengsong administrative village and the local government. In 1989, we randomly sampled 31 households in five Hani hamlets to assess the productivity of different livelihood options and income generated from traditional cash crops such as rattan, tea, and bamboo. In 1997, with a detailed inventory, our team randomly selected 20 more households in one Hani hamlet and surveyed land, livestock, households, and incomes.

\section{RESULTS}

\section{Swidden Landscape and its Evolution}

The Hani practiced traditional "Qaiya-aneya" (upland rice-rattan, swidden-fallow) agroforestry for about a century to cope with the depletion of wild rattan from the forest (Fig. 3). A typical swidden landscape ("taunya" in Hani) had uplandrice fields ("qaiya") and maize fields ("aduya") as annual crops, intercropping for rattan ("aneya") and bamboo ("apeya"), and tree vegetables ("wunueya") and tea ("leboya") as perennial crops for fallow fields. (Note that "taunya" is a common term used by the Hani in China and more widely in Burma to refer to upland agriculture. The British borrowed the term and applied it to teak agroforestry plantations.) Farmers planted new swidden fields of upland rice with rattan seeds. "Qaiya" was a foodcrop stage, intercropping upland rice with tuber crops such as yams and taro, and Cucurbitaceae such as Cucumis hystrix and Benincasa hispida. In 1990, there were more than 25 upland-rice varieties. The Hani had previously grown more than 100 upland-rice varieties. Diversity of rice varieties helped farmers adjust to agricultural micro-climates and conditions in the mountains. "Qaiya" took 2-3 yrs to grow. Farmers then planted rotations of rattan, bamboo, and fruit trees when yields decreased. As secondary forest and rattan grew, "qaiya" evolved into "aneya," a rattan-bamboo garden with diverse species. Farmers could harvest rattan and earn cash from rattan and bamboo 7 yrs after planting. Use varied according to sites over time (Fig. 3).

Policy uncertainty

Before 1949, Hani tradition prohibited harvesting from watershed and cemetery forests, and forests around each hamlet at elevations of approximately $1600 \mathrm{~m}$. Farmers cultivated swidden fields at elevations from 1000-1300 m, with access and use changing after regeneration into forests (in about 13 yrs). The landscape then supported vast primary forests and wildlife such as wild boar, barking deer, tigers, and pangolins (Sturgeon 2005). The people paid taxes to the Tai principality of Sipsongpanna, which became part of the Dai Autonomous Prefecture, Xishuangbanna province, in 1949. The state sent teams to promote sedentarization by establishing houses and paddy in the midlands or lowlands in a first attempt to accelerate local development and control land use.

The state has promoted several (sometimes conflicting) policies since 1950, affecting land ownership and biodiversity conservation in agricultural landscapes and protected-forest areas (Xu and Wilkes 2005, Melick et al. 2007). The state prohibited opium cultivation in the early $1950 \mathrm{~s}$ (Table 1) and, as a result, swidden cultivation rose from 144 ha in 1949 to 261 ha in 1956 to boost local food production (Fig. 4). Although the expansion of land in swidden broadly tracks the growth of population, deviations occurred during changes to policy. Three periods of rapid expansion of swidden in 1965, 1970, and 1979, followed by immediate reductions afterward, were probably consequences of the following provincial agricultural policies: "grain self-sufficiency" (1964), "grain request from uplands" (1969), and "exploitation of marginal lands" (1978) (Table 1). The amount of swidden land remained relatively stable except for a peak around 1979 and a drop after 1999 during implementation of the "sloping land conversion program" (Fig. 4).

The government introduced the "household responsibility system" in late 1978, allocating land rights and usage to households and villages, in part to rebuild private assets (Table 1). The policy facilitated the establishment of smallholder production and asset-building processes.

The local authorities in Mengsong allocated paddy and upland fields according to household occupancy from 1982-1984 to stabilize forests and swidden fields (Table 1). This gave farmers formal rights to land use for 30 years. In 1999, this was renewed for another 30 years. The authorities classified land as swidden $(39 \%)$, collective forest $(29 \%)$, grazing land $(18 \%)$, tea gardens $(5 \%)$, paddy $(5 \%)$, and firewood forest (4\%). Households received land for wet-paddy and swidden cultivation (Sturgeon 2004) and hamlets received collective forests. Authorities 
Figure 3. Hani taungya swidden-fallow management in Mengsong.

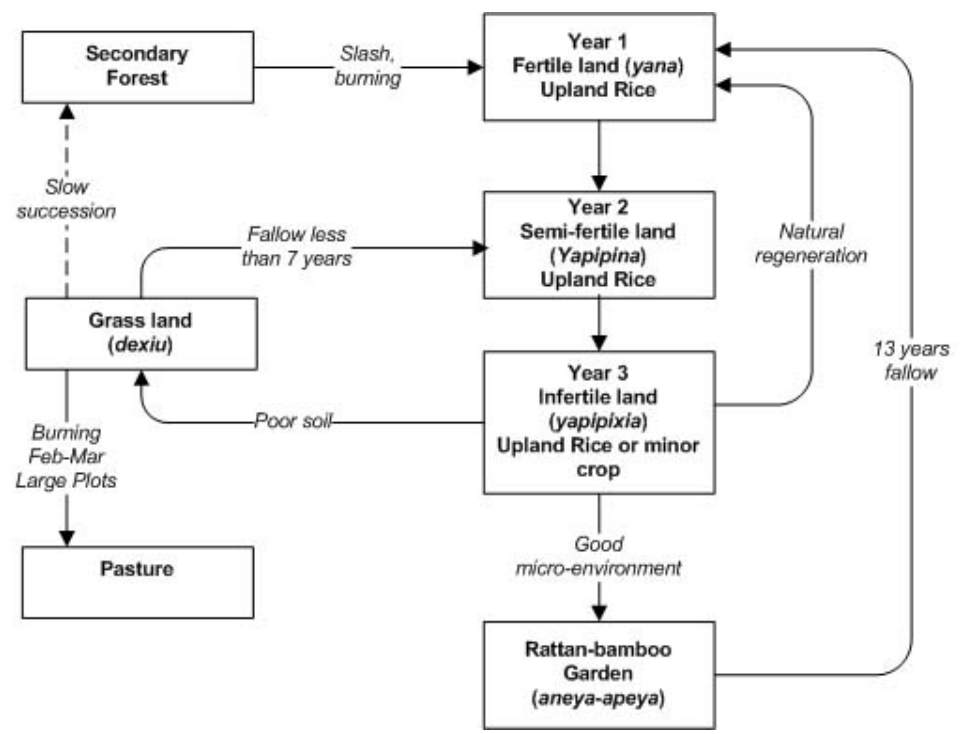

restricted timber harvesting to collective forests and allocated small household plots for multiple uses, including for firewood. The average land per capita was 1.56 ha including fallow fields. As a consequence of household-level decisions, land under swidden remained stable during the 1990s (Fig. 4).

Land under swidden decreased sharply in 2001 (Fig. 4), following implementation of the earlier government logging ban. On 1 October 1998, the government had announced its "natural forest protection program" in response to devastating floods in the Yangtze that were believed to be the result of deforestation (Table 1). The ban affected 8.5 million ha, representing about a third of the Yunnan forest area (Xu and Wilkes 2005). Immediately afterward, the "sloping land conversion program" had significant impacts, particularly on mountain-swidden cultivation (Table 1). Farmland located on slopes $>25^{\circ}$ was converted into forest or grassland. Local farmers were to be given U.S. $\$ 90$ for each ha converted (to buy tree seedlings), $2250 \mathrm{~kg}$ of grain/yr for $5 \mathrm{yrs}$ for economic plantations, and for 8 yrs for ecological plantations. The grants were renewed in 2007 and are arguably among the largest payments ever made by a state for an environmental service. Such high payments may be hard to sustain.
The government's earlier policies (Table 1) to sedentarize swidden cultivation were either unclear or overridden by subsequent conservation-oriented policies (Table 1) to increase forest cover and reduce agricultural activities in the uplands (Sturgeon 2007, Xu and Melick 2007). The net effect was increased forest cover in Mengsong, but possibly at the expense of local livelihoods due to lack of alternative income sources. Moreover, although $12 \%$ of land was in protected areas, the authorities still allowed rubber plantations and other developments in the tropical rainforest of Xishuangbanna (Li et al. 2007, Stone 2008). Most rainforest in low elevations was converted into state-owned rubber farms during the 1960s and $1980 \mathrm{~s}$, and swidden-fallow vegetation into smallholder rubber farms after the 1980s (Xu et al. 2005a). Throughout these policy changes, local institutions, beliefs, and values evolved and helped to shape a sense of responsibility toward the environment (Xu 2006b). For example, Dai cultural beliefs in the Holy Hills were strengthened to include restoring tropical forests (Liu et al. 2000).

\section{"Legible" rubber and forest transition}

Officials believed that swidden farming was primitive and that monocrop plantations were economically beneficial. Therefore, they promoted 
Table 1. Key policies affecting land use in Mengsong.

\begin{tabular}{lll}
\hline \hline Year & Policy & Intention \\
\hline 1950 & Prohibition of opium cultivation & End opium cultivation \\
1958 & Great leap forward & Expand mining for steel refining \\
1964 & Grain self-sufficiency & Increase food security \\
1969 & Grain request from uplands & Food is everything \\
1978 & Exploitation of marginal lands & Increase grain protection \\
1978 & Household responsibility system & End collective agriculture, increase grain \\
1982 & & production \\
1990 s & Forest land allocation & Sedentarize swidden \\
1998 & Poverty alleviation programs in Xishuangbanna & Expand areas of terraced tea and rubber \\
1999 & Natural-forest protection program & Conservation, logging ban \\
2006 & Sloping land conversion program & Conservation, grain for green \\
\hline
\end{tabular}

rubber as a landscape that was "legible" to them (Scott 1998, Sturgeon 2004, Xu 2006b), even though growing rubber in the cold climate of Yunnan is difficult. Farmers responded by growing some rubber, however, this was not done on all of their land. Smallholdings yield less per unit area but occupy a similar area to state farms.

Since the early 1990s, the Poverty Alleviation Bureau of Xishuangbanna and other government agencies with mandates for poverty alleviation in the uplands have invested in extension activities aimed at expanding terraced tea and rubber farms in Mengsong (Table 1). The Hani have subsequently increased cash-crop cultivation of tea and rubber in swidden-fallow fields (Table 2). The bureau has no data for 2006, but we know from remote sensing (Table 2) that about $1.5 \%$ of the area remained in swidden. In 2007, both the local government and community stated that there were no swidden fields remaining (see Fig. 4). The socioeconomic and political transformation of swidden cultivation in Mengsong appeared to be complete.

We assessed that the area covered by closed-canopy forest in Mengsong decreased from 38\%-15\% between 1965 and 1993, accompanied by forest fragmentation, and then increased from 15\%-59\% between 1993 and 2006, with clear forest regeneration. The amount of land covered by opencanopy (including fallow fields) forest grew from $22 \%$ in 1965 to $37 \%$ in 1993 and then dropped to $8 \%$ of the landscape in 2006 . The area covered by grass, bamboo, and bushes grew from 35\%-43\%, between 1965 and 1993, and then dropped to $22 \%$ in 1996 (Table 2). Most secondary growth or successional vegetation was lost to tea and rubber plantations from 1993-2006. In Table 2, secondary growth includes managed rattan and fallow fields and swidden refers to the rice and annual-crop stages only. Recent changes in land use have led to a more homogenous, less fragmented landscape (Table 2).

\section{Biodiversity}

\section{Succession in swidden fallows}

Forest measurements taken in 1997 showed a high degree of biodiversity in protected forests, used forests, and regenerating swiddens. We observed 34-80 plant species in the sampling plots (Sturgeon 
Figure 4. Impacts of policy changes on swidden cultivation in Mengsong.

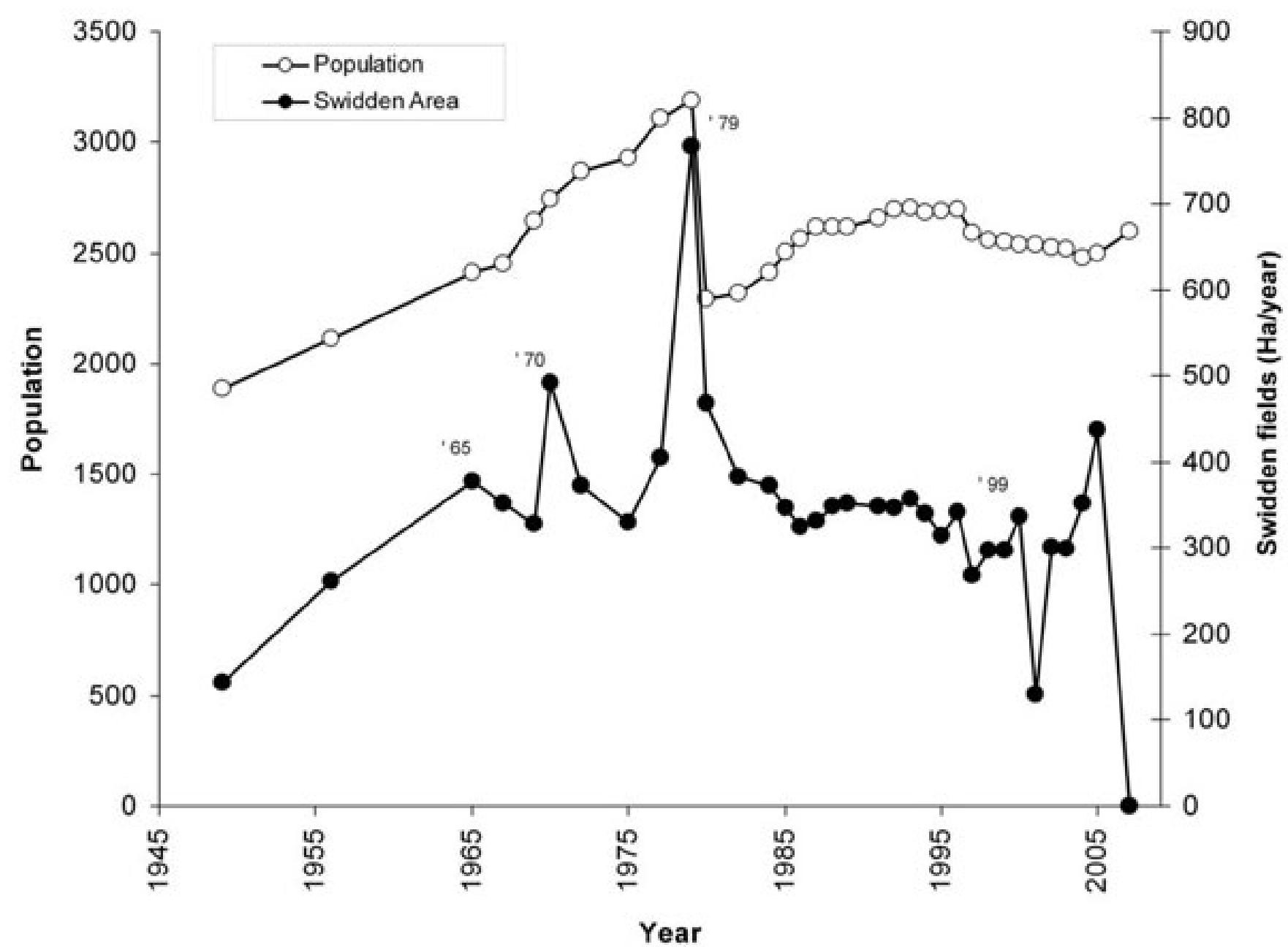

2005). The diversity of species was related to the diversity of livelihoods and remaining cultural practices that relied on forest products. Hani farming practices, such as those for rattan and tea, mimicked key natural ecosystem processes (Xu 2006c).

We compared samples in different stages of succession to detect changes in vegetation structure and composition with succession in swidden fallows. The total number of species showed no significant trends over time since cultivation began. Floristic composition of the fallow changed from a predominance of herbaceous species in young fallow to primarily shrub species later, and subsequently to tree species. The predominant species changed from sun-loving in the early periods to shade-tolerant species in successional fallows. As a consequence, plots cleared in similar periods had similar species composition (Fig. 5). After 38 years, secondary-forest fallows still had compositions distinct from those of natural forests (Fig. 5).

Farmers' management practices influenced levels of biodiversity in swidden fallows. Traditionally, people collected at least 120 species from closedcanopy (mature) forests and open-canopy or 
Table 2. Land-cover and fragmentation statistics in Mengsong in 1965 and 1993 (interpreted from aerial photographs (1965), Landsat TM (1993), and Spot (2006) images). Total area $=9965$ ha.

\begin{tabular}{|c|c|c|c|c|c|c|c|c|c|}
\hline \multirow[b]{2}{*}{ Land cover } & \multicolumn{3}{|c|}{ Percent Area } & \multicolumn{3}{|c|}{ Number of Fragments } & \multicolumn{3}{|c|}{ Average Fragment Size (ha) } \\
\hline & 1965 & 1993 & 2006 & 1965 & 1993 & 2006 & 1965 & 1993 & 2006 \\
\hline Secondary growth & 95 & 95 & 89 & 136 & 554 & & 69 & 17 & \\
\hline Closed canopy & 38 & 15 & 59 & 19 & 24 & 17 & 198 & 63 & 346 \\
\hline Open canopy & 22 & 37 & 8 & 68 & 271 & 11 & 33 & 14 & 74 \\
\hline Grass and bushes & 35 & 43 & 22 & 49 & 259 & 47 & 71 & 17 & 47 \\
\hline Swidden & 2 & 2 & 1.5 & 56 & 60 & 35 & 3 & 3 & 4.5 \\
\hline Paddy & 3 & 2 & 2 & 4 & 2 & 15 & 65 & 71 & 15 \\
\hline Terraced tea & & & 3 & & & 5 & & & 58 \\
\hline Rubber & & & 2.7 & & & 8 & & & 33 \\
\hline Reservoir & 0 & 0.4 & 0.2 & 0 & 1 & 1 & 0 & 40 & 24 \\
\hline Other & 0 & 0.6 & 0.8 & & 13 & 7 & & 4 & 12 \\
\hline Total & 100 & 100 & 100 & 196 & 630 & & 51 & 16 & \\
\hline
\end{tabular}

secondary forests (Xu 1990). Local farmers planted about 100 species in swidden fields, which were sources of biodiversity (Xu 1990). Farmers did not leave fallow fields idle, but rather, actively managed them. The Hani collected timber and nontimber forest products as an important livelihood activity. Natural evergreen broadleaf forest, montane rainforest, and tropical seasonal rainforest displayed rich diversity at both sites.

Biodiversity in Mengsong was multi-level, and manifest at genetic, population, community, ecosystem, landscape, and regional levels. It included forest diversity, agrobiodiversity, wildlife, and useful plants. Human culture was also a component of this diversity.

\section{Ecosystem goods and services}

The Hani received numerous goods and services from the biodiversity of swidden landscapes (Fig. 2), as did the Dai downstream, and people beyond in mainland southeast Asia. The number of bird species in swidden-fallow succession was equivalent to or higher than numbers in matured forest (Wang and Young 2003), although conservation values might differ. The agricultural biodiversity illustrated the functional link of biodiversity to economic and sociocultural objectives. Ecological functions of biodiversity included hydrologic, food chain, nutrient cycling, carbon sequestration, ecological succession, and others. Sociocultural functions of biodiversity were reflected in daily interactions with biological resources (food, fodder, shelter, medicine, weaving materials, cultural beliefs, aesthetics, and recreation). Socioeconomic functions were related to marketing products or exchanging them with other people or communities, as well as maintaining social-safety nets.

The government overlooked the ecosystem services (water-related services, biological and cultural diversity, and carbon sequestration) provided by Mengsong over decades and centuries, although the value of these overall was generally greater than any 
Figure 5. Multi-dimensional scaling of the species similarity matrix comparing plots from different stages of swidden-fallow succession. Plots with greater similar species composition are plotted more closely together in the figure. Numbers after ' $\mathrm{Y}$ ' indicate number of years since cleared for cultivation. $\mathrm{NF}=$ natural forest. $\mathrm{A}, \mathrm{B}$, and $\mathrm{C}$ suffixes indicate replicate plots of same age.

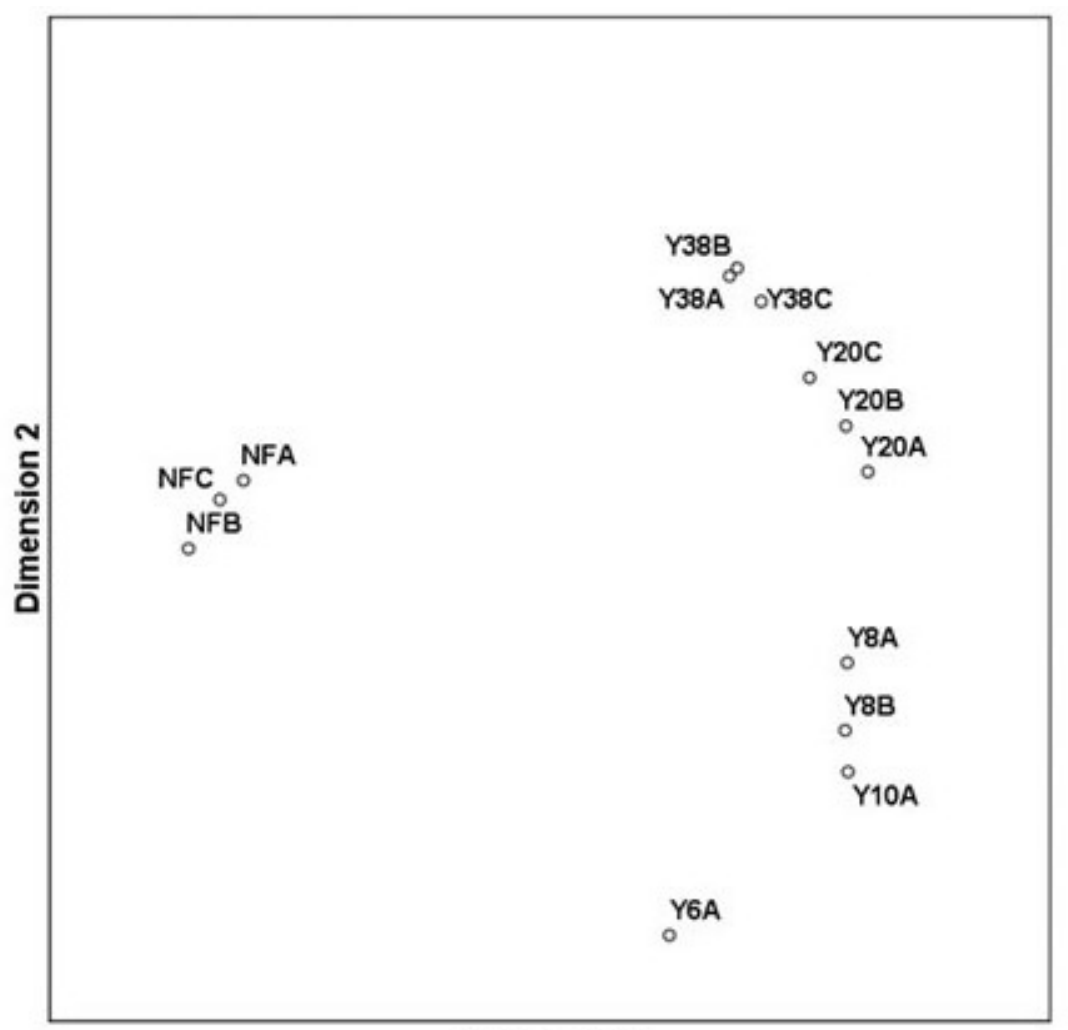

Dimension 1

use value derived from direct consumption. Local forestry officials in Mengsong interpreted "natural forest protection and sloping land conversion" policies (Table 1) to mean that forests with trees $>5$ $\mathrm{cm}$ in diameter at breast height (dbh) in swiddenfallow were natural forests and not available for swidden despite the contracts given to farmers after sedentarization in the early 1980s (Sturgeon 2007). The payments for the "sloping land conversion program" either did not reach remote frontier areas, or swidden cultivators were bypassed when payments were given to other priority areas that were more accessible and visible to outsiders.

The government promoted forest conservation and an increase in forest cover from swidden-fallow vegetation (Table 2) at the expense of local swidden

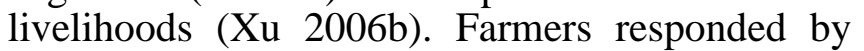
intensifying swidden cultivation by intercropping, once suitable cash crops and agrotechnologies were introduced.

\section{Culture}

\section{Resilient institutions}

Customary Hani institutions have persisted despite four decades of political turbulence and cultural disruption, helping them organize access and use of land and biodiversity. One practice that has survived is community ownership and management of rattan 
forests. The Hani continue to gather rattan to build houses or make coffins. Traditional Hani forest management was functional. Forests are protected for rattan ("sangpabawa") and fire-resistant broadleaf trees (Schima wallichii) are protected around villages as firebreaks (Chen et al. 1993). The Hani also have rules for protecting an extensive ring of forest around the village ("pucanq"), areas of ancestral or cemetery forest ("laoqbiml"), and watershed-protection forest ("gaomail-sanqhav"). Hani people believe that the sacred forest ("milsanlsanqqu") housed the earth's mother, and this was often represented in art by a strong and long-lived tree such as oak (Castanopsis mekongensis) or pipal (Ficus religiosa).

Concomitantly, external political changes introduced new institutions with consequences for naturalresource management and location-dependent livelihoods. The most important change was related to decentralization. The 1998 "organic law of the village committee" created more opportunities for self-organization at village levels (Xu and Ribot 2004). Reforms related to the "forest law" in 1998 recognized rights over forest land, and were strengthened by the "collective forest tenure reform" policy in 2006 (Table 1).

\section{Social networks}

The persistence of local traditions in the use and management of biodiversity did not mean that such traditions were static. The Hani demonstrated a great capacity to acquire new knowledge and agricultural practices, and to negotiate new institutional arrangements when faced with challenges and constraints, partially through their capacity to build and maintain effective social networks.

In Mengsong, most families maintained relationships with Dai families in the lowlands (Liu et al. 2000), Bulang families at middle elevations, and Bulang or Hani families in Myanmar. Mengsong Hani had extensive networks with other Hani, including different subgroups in southwest China and southeast Asia. They maintained these networks through reciprocal visits during festivals and by exchanging products after harvest. Through social networks, the Hani obtained crucial information about livelihood options, information about individuals who could influence their access to natural resources, and opportunities to exchange useful species and genetic resources. Networks acted as safety nets during community-level crises, and provided a vehicle for the exchange of knowledge and labor. Hani from China were invited by relatives and friends to Laos and Myanmar to demonstrate new technologies and cash crops.

\section{Local ecological knowledge}

Hani swidden cultivators had an intimate understanding of micro-sites, changes in land cover, vegetation succession over time, and the relations of biota and abiota during material and energy flows (Wang et al. 2000). For example, lands with fig trees (often rocky), with parasitic trees, or habitat with slow loris (Nycticebus intermedous), were considered as sacred, and could not be opened for swiddening (Wang et al. 2000). Such habitats are considered by scientists to have high concentrations of biodiversity, with fig trees being a key-stone species hosting other fauna, but have poor soil fertility (Xu et al. 2005a).

Spiritual beliefs often reinforced other forms of knowledge. Species and vegetation had their ecological and cultural functions in the swidden landscape (Xu et al. 2005b). The Hani set fallow periods at 13 years, considered a lucky number and long enough for soil regeneration under fallow. Turning over trees while slashing was considered bad luck, and they did not cultivate certain swidden fields for fear of bringing bad luck to the village.

\section{Culture-biodiversity links}

The Hani were traditionally animists and emphasized ancestor worship. Cemetery forests were traditionally strictly protected, trees and animals were believed to have supernatural powers, and different spirits had their own habitats ( $\mathrm{Xu}$ et al. 1999). The Hani believed that disturbances to the supernatural caused illness. Local customary authorities, like headmen ("palu"), village chiefs ("zoema"), and clan heads ("pamou") dealt with matters like delineating forest boundaries and selecting swidden sites in the forests. As of 1990, the village chief or his shaman ("biemo" and "nipa"), still performed traditional rituals for festivals and other activities (Fig. 6).

Linking culture with ecosystem management is important for adaptive management (Folke et al. 2003). Sacred plants and forest patches acted as reservoirs for renewal and innovation in Hani villages. Rituals and the landscape helped maintain and reinforce their cultural identity (Xu et al. 2005a) 
Figure 6. The swidden agricultural calendar of the Hani community in Mensong, as illustrated by a local artist.

a) selection of land and marking, performed by male adults of the family during January and February; b) selective cutting of trees, performed by both men and women during February and March; c) burning, performed by men and women 33 days after cutting; d) house building in April; farmers stay in these houses, in the fields when farming is busy, since the fields usually are far from the village; e) cleaning the land, performed by everyone during late April and early May: f) sowing, men dig the holes, women put the seeds, it takes place when the cuckoo bird sings, in May; g) weeding and loosening the soil by men, women and old people, two or three times a year from June to September; h) harvest, carried out by everyone in October

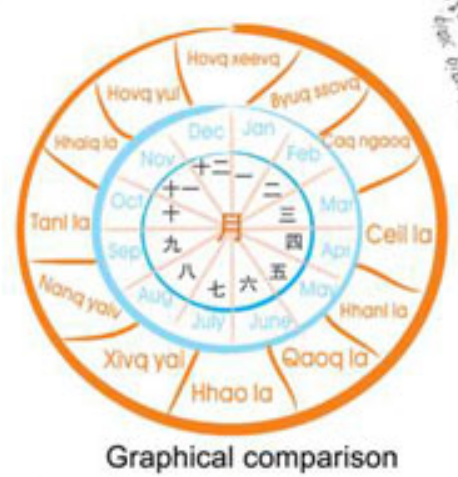

between the Hani calendar and the Gregorian calendar

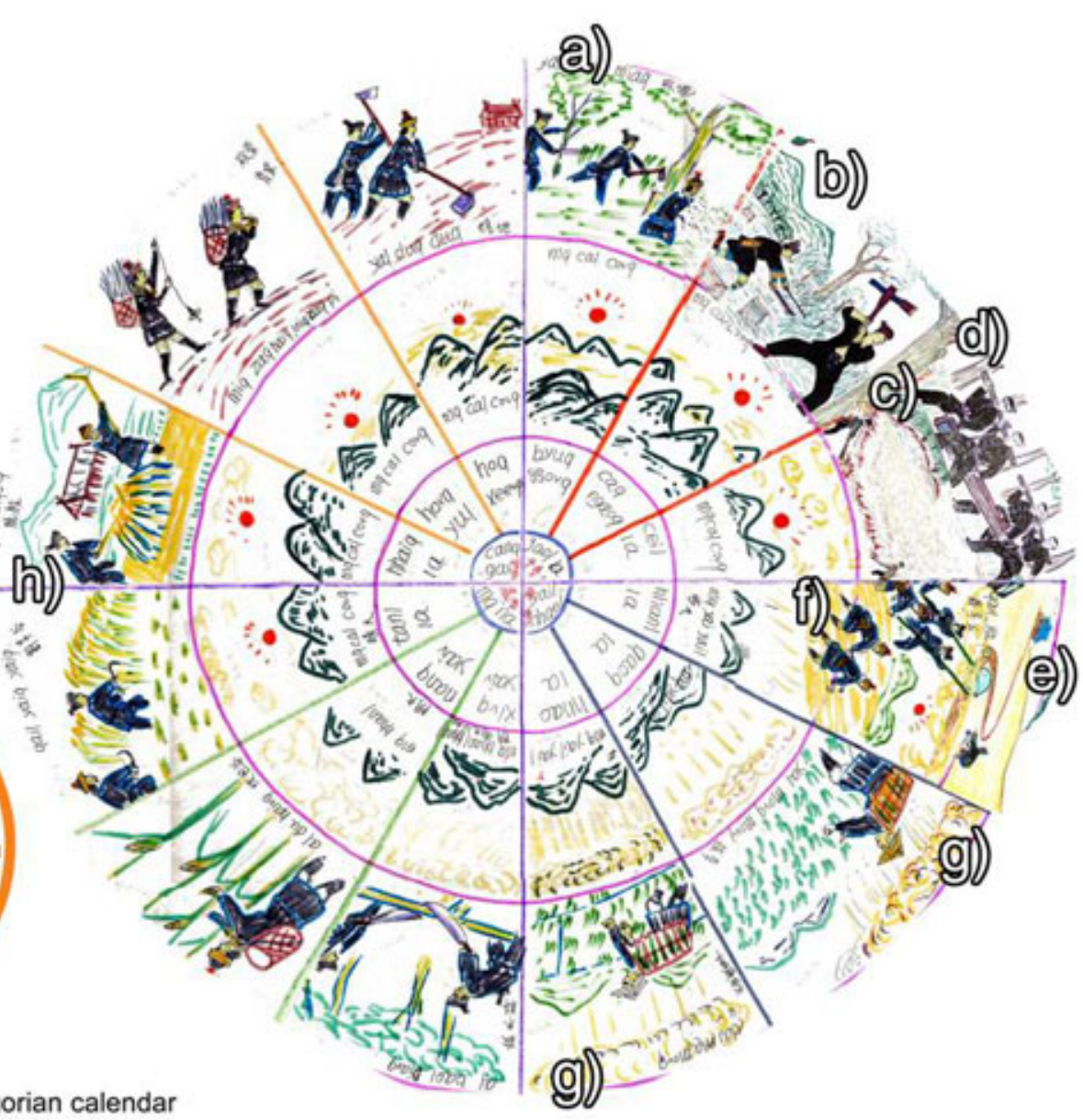

even as culture itself responded to external influences such as tourism.

The idea that links between biodiversity and culture are static and restricted to "indigenous," "local," or "traditional" people is erroneous (Cocks 2006) and does not capture the flexible combinations of cultural practices and institutions taking place as circumstances change in reaction to external constraints and opportunities to ensure sustainable use of resources and conservation of biodiversity. Many aspects of the Hani lifestyle and livelihoods changed in response to economic opportunities, but aspects of culture persisted and became significant factors in the use and conservation of biodiversity (Xu et al. 2005b).

\section{Livelihoods}

\section{Multiple products from the landscape}

Before its reconfiguration, the swidden landscape mosaic (Fig. 2) provided not only upland and wetrice varieties for different occasions but also a polyculture of tea, bamboo, rattan, and fruit trees, 
as well as other nontimber forest products such as wild fruits, mushrooms, and vegetables. The Hani based their livelihoods on a composite of activities that allowed a shift in labor allocation and adjustments to biophysical and socioeconomic extremes (Sturgeon 2005). For example, average returns from labor (measured as $\mathrm{kg}$ of rice/day) can vary greatly with the location of rice fields: paddy $(9.5 \mathrm{~kg} /$ day $)$, forest-based swidden $(6.4 \mathrm{~kg} /$ day $)$, and grassland-based swidden (3.6 kg/day) (Xu 2006c). Households engaged in a combination of activities and had multiple sources of income. In 1989, common sources of income were animal husbandry, and fruit and tea gardens (Table 3). Pig farming was the most lucrative activity, and on average, provided $42 \%$ of income. Intercropping, agroforestry, and improved swidden fallows provided large quantities of forage for pigs (e.g., maize, banana stems, and leaf fodder).

This combination of land uses produced risk-averse, flexible livelihood strategies. Villagers' understanding of the changing nature of land cover enabled them to formulate long-term strategies. For example, farmers could harvest rattan from improved fallow fields while market prices were high (Xu 2006c). The younger generation spent more time working at off-farm jobs in cities. With these changing needs, they could convert pastures into permanent forest. Such flexibility in the social-ecological systems proved to be an important source of resilience for the Hani when facing challenging external policies or unfavorable economic environments (Sturgeon 2005).

New markets

Villagers changed their land-management practices in the 1980s in response to policies that devolved responsibility to households and encouraged market production. Households at lower elevations and with sufficient water converted swidden fields into terraced rice paddies. Wet rice required peak periods of labor for planting, weeding, and harvesting, but at other times villagers could engage in other work. In contrast, swidden fields had to be tended almost year round. Once households switched to wet rice, women in the uplands spent more time growing vegetables rather than rice, and collecting mushrooms, wild fruits, and vegetables in demand by Dai and Han traders (Sturgeon 2005).

The Hani began to sell plants previously consumed at home. Outsiders came to the Mengsong area to work as miners in the late 1980s, both locally and across the border in Myanmar. The Hani sold them mountain niche items and increased their home gardens for vegetable production. They also sold upland products to lowland markets in Damenglong, a town about $30 \mathrm{k}$ from Mengsong (< $1 \mathrm{~h}$ by bus). Middlemen visited from time to time to buy local products for sale or processing. The local market in Mengsong operated during the mining boom in the late 1980 s, primarily selling swidden products to local restaurants and mining workers. After 1996, (Table 1) the state banned exploitation of manganese and tin in Mengsong, and the remaining customers were mainly the border army, cross-border mining-truck drivers, middlemen, and increasingly, local villagers.

Another response to the opening of markets was an increase in livestock. People ate domestically raised livestock rather than wild game after the provincial government banned hunting in 1996. Before 1996 (that is, before the hunting ban), livestock numbers had tripled since 1982, and incomes from livestock were second only to mining incomes. As a result, young villagers converted upland-swidden lands into pastures, reverting upland swiddens to collective use for grazing, despite their earlier allocation to households (Sturgeon 2005). Although the younger generation made these land-use changes, older women made different adjustments to new policies and to changed land uses by opening up the swiddens again in new areas to spread the risks of crop failure.

\section{Intensification}

Tin mining in Mengsong started in 1989 and caused environmental damage. After its collapse in 1996, the Hani intensified swidden cultivation by shortening fallow cycles from $>13-y r$ to $3-5-y r$ cycles. Even highly degraded grasslands were converted to swidden by farmers without alternative incomes. Farmers used herbicides heavily to reduce labor for weeding and facilitate long cultivation and short fallow cycles.

The Hani also intensified cultivation by reallocating swidden-fallow fields. Each household put its allocation into a common pool, opening up large areas for cash crops. After slashing, burning, fencing, and road building, they reallocated plots to the household, reducing overall labor inputs. Cash crops, such as tea and fruit trees, become predominant. 
Table 3. The main sources of cash income in Mengsong in 1989 (Xu 2006b). U.S. $\$ 1=$ CNY 3.7 at 1989 exchange rate.

\begin{tabular}{lccc}
\hline \hline Source of income & $\begin{array}{c}\text { Total Production } \\
\text { Units }\end{array}$ & $\begin{array}{c}\text { Price } \\
\text { U.S.\$/Unit }\end{array}$ & $\begin{array}{c}\text { Percent } \\
\text { Total Income }\end{array}$ \\
\hline Tea & $39900 \mathrm{~kg}$ & 0.8 & 15.0 \\
Fruits & $412500 \mathrm{~kg}$ & 0.1 & 15.5 \\
Rattan & $39000 \mathrm{~kg}$ & 0.4 & 7.3 \\
Bamboo (stem) & 23180 pieces & 0.5 & 5.8 \\
Dry bamboo shoots & $2240 \mathrm{~kg}$ & 0.5 & 0.5 \\
Mushrooms & $2656 \mathrm{~kg}$ & 1.5 & 1.8 \\
Basket weaving & 3496 pieces & 2.0 & 3.1 \\
Pigs & 1129 heads & 81 & 42.4 \\
Cattle & 171 heads & 108 & 8.6 \\
\hline
\end{tabular}

\section{Diversification}

The Hani maintained diverse inputs and income sources as a fundamental livelihood strategy. When intensification and other livelihood transformations occurred, they reintroduced diversification at either the household or the community level, extending to income-generating activities beyond the immediate farm. A notable example of this was the commercialization of the Hani tradition of providing massages for visitors or relatives after a meal as a tourist service in the restaurants, hotels, and sex industry of Jinghong. Note that labor migration caused an imbalance in the gender ratio of persons of marriageable age in Mengsong (57 females to 143 males).

The sociocultural functions of biodiversity have changed. In the past, the Hani managed swidden fallows (Fig. 3) by maintaining a dynamiclandscape mosaic with patches in different successional stages (Fig. 2). With the end of swidden cultivation (Fig. 4), the landscape became homogenous with distinct forest and agricultural elements, and decreasing areas of secondary vegetation (Table 2). Links between cultural practices and biodiversity also changed. Biodiversity now has less cultural meaning for young villagers.
Traditional culture is performed during festivals, rather than practiced in daily life. Tourism could forge new links with this static landscape through promoting nontimber forest products and landscape elements. However, such links might require different forms of active management to avoid overexploitation by recognizing the risks in uniformity of land uses.

The Hani managed to manipulate state regulations to maintain landscape "plasticity," by planting rattan and bamboo into state forests, or incorporating cash crops such as tea and fruit trees into swidden-fallow fields, but forestry staff perceived them to be "backward" because they practiced swidden, and they intended to reclassify swidden as collective forest (Sturgeon 2005).

Sedentarization reduced flexibility in land use and diversity. The fact that the Hani flexibly adopted new crops and land uses continued to confound state plans for "simplicity" (Sturgeon 2005). Markets were the driving force behind villagers' manipulations of state-property allocations, but the rotating landscape and biodiversity created by swidden cultivation disappeared because of state control of land use and promotion of the plantation industry. 


\section{DISCUSSION}

\section{Broken Links}

Biological diversity can actually be maintained and enhanced by disturbance and human activities. Swidden agroecosystems, like those historically practiced by the Hani, have successfully maintained functional links between sustainable livelihoods, culture, and biodiversity. Current development and conservation policies tend to sever these links, leaving upland farmers in monocultural landscapes where they are more vulnerable to market shifts. Their profound ecological and cultural knowledge is untapped.

The large-scale conversion from swidden-fallow vegetation into nonnative plants such as rubber, for example, has resulted in the depletion of soil moisture and an increase in surface runoff (Guardiola-Claramonte 2008). Secondary vegetation loss also has implications for carbon dynamics and climate change in the region. Li et al. (2008) conclude that 6 million tonnes of biomass carbon stock were lost in Xishuangbanna from 1976-2003.

Development and conservation policies in neighboring countries have also tended to sever links between sustainable livelihoods, culture, and biodiversity. In Thailand, for example, diverse swidden systems in the uplands of the north have been treated as universally destructive and a barrier to conservation. The rights of minorities to use forests and convert land for agriculture have largely been ignored (Ganjanapan 1998, Sturgeon 2005) in the pursuit of conservation objectives (Laungaramsri 2002). Laos has pursued direct policies of resettlement and the introduction of cash cropping to sedentarize swidden systems, but with mixed success (Ducourtieux et al. 2006).

\section{Innovations}

A return to traditional swidden systems is unlikely. Throughout the tropics of southeast Asia, swidden has already largely been replaced by other land uses. Needs and aspirations have reasonably shifted with economic development. Households and individuals now expect much higher returns for their labor and better education and health for their children (Thomas et al. 2008).
Development and conservation policies are leading to the complete conversion of swidden landscapes to monoculture plantations in many places across mainland southeast Asia. But in some locations, cash crops are grown alongside traditional and diverse land-use types, such as rice paddies, home gardens, multi-purpose agroforestry and conservation forests, and residual swidden-fallow fields (Fox et al. 2000). These mixed landscapes are important for maintaining and even enhancing agrobiodiversity (Rerkasem et al. 2009). Rebuilding and maintaining landscape diversity appears to be a key strategy.

Ways to maintain and rebuild functional links in new, dynamic, landscape configurations and development contexts would be highly desirable. Local ecological and cultural knowledge is likely to be important to such efforts (Cairns 2007). Some important experiments are underway in Mengsong and elsewhere in the world where swidden systems formerly dominated. The development of diverse upland gardens or improved fallow management (e. g., Cairns 2007) demonstrates the potential for hybrid, tailored knowledge and technology to assist livelihood improvements and maintain ecosystem functions associated with agrobiodiversity and cultural identity (Xu et al. 2005a). The challenge is to find ways to upscale these promising innovations.

\section{Upscaling}

Enabling government policies concerning upland forest, land, and markets are likely to be critical to the scaling up of promising initiatives (Thomas et al. 2008). In some cases, the problem seems to be primarily about removing disincentives to investment in land and natural-resource management, such as when formal policies and government practices override otherwise functional local systems of property rights to land, water, and forest products.

In other cases, capacity building to help households successfully engage in markets for new agricultural commodities that are grown sustainably (such as shade coffee), or services such as tourism, appears necessary to ensure that the niche benefits local users and maintains those critical links to land use and landscape biodiversity. Taking a particular commercial niche and expanding it requires learning about both techniques and marketing. Certification and labeling schemes supporting the 
fair trade of organic products, for example, might help reward and expand more sustainable practices.

Government interventions may also be needed to stimulate research and development about new crops and improvements in agroforestry management, to encourage private investment, and to develop value-added industries. Finally, institutional development in remote areas where former swidden landscapes have been transformed is often key to generating new sustainable links. Here, local government, for example, may have a pivotal role to play, both in empowering local land managers and in bringing the financial and technical resources to forge new links.

\section{CONCLUSION}

The diversity of livelihoods and ecosystems in Mengsong is under threat. Livelihood uncertainties make predictions about future biodiversity difficult. The state's past efforts at sedentarization took hold through conservation policies and market-based incentives for intensification. Sedentarization of agriculture changed the structure of the landscape, almost eliminating the diversity of successional stages.

Ways of building new functional links among sustainable livelihoods, culture, and biodiversity are needed, rather than seeking to recreate old links. Efforts at realignment and reconciliation to save species and environments without displacing people or their economic activities are now being made (Rosenzweig 2003) and less restrictive state policies are creating opportunities for self-organization and innovation.

Responses to this article can be read online at: http://www.ecologyandsociety.org/voll4/iss2/art20/ responses/

\section{Acknowledgments:}

This work was funded by various sources including: a) Hani (Akha) Agroecosystem Analysis in 19891990; b) Biodiversity Assessment in Swidden Agroecosystem in Xishuangbanna during 19931996, supported by the Ford Foundation; c) research on property rights and landscape transformations from 1930 to 1997 (1996-1997); d) Biodiversity and Sustainable Livelihoods in Southeast Asia in 2002-2003 supported by the AsiaPacific Network for Global Change Research; e) Understanding Dynamic Resource Management Systems and Land Cover Transitions in Montane Mainland Southeast Asia in 2003-2006, supported the National Science Foundation of the United States, and f) Making the Mekong Connected: Developing Carbon and Biodiversity Assets for Multifunctional Landscapes in the Upper Mekong, supported by the BMZ/GTZ, Germany. Thanks to Rajesh Daniel and Greta Rana for comments on earlier drafts of this paper.

\section{LITERATURE CITED}

Berkes, F. 2006. From community-based resource management to complex systems. Ecology and Society 11(1): 45. [online] URL: http://www.ecolo gyandsociety.org/vol11/iss1/art45/

Brookfield, H., C. Padoch, H. Parson, and M. Stocking. 2003. Cultivating biodiversity: understanding, analysing and using agricultural diversity. Intermediate Technology Development Group, London, UK.

Cairns, M., editor. 2007. Voices from the forest: integrating indigenous knowledge into sustainable upland farming. Resources for the Future, Washington, D.C., USA.

Chen, S. Y., S. J. Pei, and J. C. Xu. 1993. Indigenous management of the rattan resources in the forest lands of mountain environment: the Hani practice in the Mengsong area of Yunnan, China. Ethnobotany 5:93-99.

Cocks, M. 2006. Biocultural diversity: moving beyond the realm of "indigenous" and "local" people. Human Ecology 34:185-200.

Conklin, H. C. 1957. Hanunoo agriculture: a report on an integral system of shifting cultivation in the Philippines. Food and Agriculture Organization (FAO), Rome, Italy.

Ducourtieux, O., P. Visonnavong, and J. Rossard. 2006. Introducing cash crops in shifting cultivation regions - the experience with cardamom in Laos. Agroforestry Systems 66(1):65-76. 
Folke, C., J. Colding, and F. Berkes. 2003. Synthesis: building resilience and adaptive capacity in social-ecological systems. Pages 352-387 in F. Berkes, J. Colding, and C. Folke, editors. Navigating social-ecological systems: building resilience for complexity and change. Cambridge University Press, Cambridge, UK.

Fox, J., Dao Minh Truong, A. T. Rambo, Nghiem Phuong Tuyen, Le Trong Cuc, and S. Leisz. 2000. Shifting cultivation: a new old paradigm for managing tropical forests. Bioscience 50(6):521528.

Ganjanapan, A. 1998. The politics of conservation and the complexity of local control of forests in the northern Thai highlands. Mountain Research and Development 18(1):71-82.

Guardiola-Claramonte, M., P. A. Troch, A. D. Ziegler, T. W. Giambelluca, J. B. Vogler, and M. A. Nullet. 2008. Local hydrologic effects of introducing non-native vegetation in a tropical catchment. Ecohydrology 1(1):13-22.

Laungaramsri, P. 2002. Redefining nature: Karen ecological knowledge and the challenge to the modern conservation paradigm. Earthworm Books, Chennai, India.

Li, H. M., T. M. Aide, Y. X. Ma, W. J. Liu , and M. Cao. 2007. Demand for rubber is causing the loss of high diversity rainforest in SW China. Biodiversity and Conservation 16:1731-1745.

Li, H. M., Y. X. Ma, T. M. Aide, and W. J. Liu. 2008. Past, present and future land-use in Xishuangbanna, China and the implications for carbon dynamics. Forest Ecology and Management 255:16-24.

Liu, H., Z. Xu, and Y. Xu. 2000. The role of the traditional beliefs in conservation plant diversity: a case study in Xishuangbanna, southwest China. Pages 812-818 in J. C. Xu, editor. Links between cultures and biodiversity. Proceedings of the Cultures and Biodiversity Congress, 20-30 July 2000. Yunnan Sciences and Technology Press, Yunnan, China.

Liu, J., M. Liu, X. Deng, D. Zhuang, Z. Zhang, and D. Luo. 2002. The land use and land cover change database and its relative studies in China.
Journal of Geographical Sciences 12:275-282.

Melick, D., X. F. Yang, and J. C. Xu. 2007. Seeing the wood for the trees: how conservation policies can place greater pressure on village forests in southwest China. Biodiversity and Conservation 16:1959-1971.

Pei, S. J., and P. Luo. 2000. Traditional culture and biodiversity conservation in Yunnan. Pages 230239 in J. C. Xu, editor. Links between cultures and biodiversity. Proceedings of the Cultures and Biodiversity Congress, 20-30 July 2000. Yunnan Sciences and Technology Press, Yunnan, China.

Pei, S. J., J. C. Xu, S. Y. Chen, and C. L. Long. 1997. Collected research papers on biodiversity in swidden agroecosystems in Xishuangbanna. Yunnan Education Press, Kunming, China.

Rerkasem, K., D. Lawrence, and C. Padoch. 2009. Consequences of swidden transitions for crop and fallow biodiversity. Human Ecology, in press.

Rosenzweig, M. L. 2003. Win-win ecology: how the earth's species can survive in the midst of human enterprise. Oxford University Press, Oxford, UK.

Scott, J. C. 1998. Seeing like a state. Yale University Press, New Haven, Connecticut, USA.

Smith, R. L. 1980. Ecology and field biology. Harper and Row, New York, New York, USA.

Spencer, J. E. 1966. Shifting cultivation in southeastern Asia. University of California Press, Berkeley and Los Angeles, California, USA.

Stone, R. 2008. Showdown looms over a biological treasure trove. Science 319:1604.

Sturgeon, J. C. 2004. Post-socialist property rights for Akha in China: what is at stake? Conservation and Society 2:137-161.

Sturgeon, J. C. 2005. Border landscapes: the politics of Akha land use in China and Thailand. University of Washington Press, Seattle, Washington, USA.

Sturgeon, J. C. 2007. Pathways of "indigenous knowledge" in Yunnan, China. Alternatives: Global, Local, Political 32(1):129-153. 
Sturgeon, J. C., and N. K. Menzies. 2008. Ideological landscapes: rubber in Xishuangbana. Asian Geographer 25:21-37.

Thomas, D. E., B. Ekhasing, M. Ekhasing, L. Lebel, H. M. Ha, L. Ediger, S. Thongmanivong, J. C. Xu, C. Saengchayosawat, and Y. Nyberg. 2008. Comparative assessment of resource and market access of the poor in upland zones of the greater Mekong region. Report submitted to the Rockefeller Foundation under grant no. 2004 SE 024. World Agroforestry Centre, Chiang Mai, Thailand.

Wang, J. H., J. C. Xu, and S. J. Pei. 2000. Study on indigenous knowledge system for management of ecosystem diversity in Mengsong Hani community, Xishuangbanna. Chinese Journal of Ecology 19(2):36-41.

Wang, Z. J., and S. S. Young. 2003. Differences in bird diversity between two swidden agricultural sites in mountainous terrain, Xishuangbanna, Yunnan, China. Conservation Biology 110:231243.

Xu, J. C. 1990. Hani agroecosystem analysis. Kunming Institute of Botany, Chinese Academy of Sciences, Kunming, China.

Xu, J. C. 2006a. Rattan and tea-based intensification of shifting cultivation by Hani farmers in southwestern China. Pages 667-673 in M. F. Cairns, editor. Voices from the forest: integrating indigenous knowledge into sustainable farming. Resources for the Future, Washington, D. C., USA.

Xu,J. C. 2006b. The political, social, and ecological transformation of a landscape: the case of rubber in Xishuangbanna, China. Mountain Research and Development 26:254-262.

Xu, J. C. 2006c. Rattan and tea-based intensification. Pages 667-675 in M. F. Cairns, editor. Voices from the forest: integrating indigenous knowledge into sustainable farming. Resources for the Future, Washington, D.C., USA.

Xu, J. C., J. Fox, X. Lu, N. Podger, S. Leisz, and X. H. Ai. 1999. Effects of swidden cultivation, state policies and customary institutions on land cover in a Hani village, Yunnan. Mountain Research and
Development 19(2):123-132.

Xu, J. C., J. Fox, P. F. Zhang, Y. S. Fu, L. X. Yang, J. Qian, S. Leisz, and J. Vogler. 2005a. Land-use and land-cover change and farmer vulnerability in Xishuangbanna prefecture in southwestern China. Environmental Management 36(3).

Xu, J. C., E. Z. Ma, T. Duojie, Y. S. Fu , Z. Lu , and D. Melick. 2005b. Integrating sacred knowledge for conservation: cultures and landscapes in southwest China. Ecology and Society 10(2): 7. [online] URL: http://www.ecologyandsoc iety.org/vol10/iss2/art7/

Xu, J. C., and D. Melick. 2007. Rethinking the effectiveness of public protected areas in southwestern China. Conservation Biology 21 (2):318-328.

Xu, J. C., and J. Ribot. 2004. Decentralization and accountability in forest management: case from Yunnan, southwest China. European Journal of Development Research 14(1):153-173.

Xu, J. C., and A. Wilkes. 2005. State simplifications of land use and biodiversity in the uplands of Yunnan, eastern Himalayan region. Pages 541-550 in U. M. Huber, H. K. M. Bugmann, and M. A. Reasoner, editors. Global change and mountain regions: an overview of current knowledge. Springer Verlag, Berlin, Germany.

Yang, L. X., J. C. Xu, J. H. Wang, and Z. W. Yang. 2001. The biological pattern of shifting cultivation improvement in tropical areas. Journal of Southwest Forestry College 21(3):146-151.

Zhang, J. H., and M. Cao. 1995. Tropical forest vegetation of Xishuangbanna, S.W. China and its secondary changes, with special reference to some problems in local nature conservation. Biological Conservation 73(3):229-238. 